\title{
On the origin of faeces: morphological versus molecular methods for surveying rare carnivores from their scats
}

\author{
Angus Davison ${ }^{1,2 *}$, Johnny D. S. Birks ${ }^{2}$, Rachael C. Brookes ${ }^{1,2}$, Tony C. Braithwaite ${ }^{3}$ and John E. Messenger ${ }^{2}$ \\ ${ }^{1}$ Institute of Genetics, Queen's Medical Centre, University of Nottingham, Nottingham NG7 2UH, U.K. \\ ${ }^{2}$ The Vincent Wildlife Trust, 3/4 Bronsil Courtyard, Eastnor, Ledbury, Herefordshire HR8 1EP, U.K. \\ ${ }^{3}$ Nant-y-Llyn, Ffarmers, Llanwrda, Carmarthenshire SA19 8PX, U.K. \\ (Accepted 14 June 2001)
}

\begin{abstract}
Charismatic mammals remain a linchpin in attracting publicity and funds for the conservation of native habitats and organisms. Unfortunately, the same animals are frequently scarce and difficult to survey. For many, confirming their presence through faecal surveys is the only cost-effective approach. Here we show that, contrary to received opinion, expert naturalists fail reliably to distinguish pine marten Martes martes faeces ('scats') from those of foxes Vulpes vulpes. Moreover, their judgement fails completely when the animals and their scats are at their most scarce. This unexpected result from such a well-studied species has important implications for the monitoring of endangered mammals. We recommend that in the future, a multi-evidence approach should be adopted to monitor elusive mammals, involving DNA methods, cast hair identification, camera traps, and non-leading 'sighting' questionaires. For national surveys, it may soon become cost-effective to screen large numbers of samples using microarray technology.
\end{abstract}

Key words: faeces, Martes, mtDNA, scats, survey, Vulpes

\section{INTRODUCTION}

Charismatic mammals remain a linchpin in attracting publicity and funds for the conservation of native habitats and organisms. Unfortunately, the same animals are frequently scarce and difficult to survey. For many, confirming their presence through faecal surveys is the only cost-effective approach - and much faith has been invested in the reliability of faeces identification in the field.

In Britain, pine martens Martes martes, foxes Vulpes vulpes, otters Lutra lutra, mink Mustela vison, and voles Arvicola terrestris are monitored from their faeces. Information on their abundance and feeding ecology is then inferred, and used to provide recommendations for conservation. In particular, scats of both martens and foxes have been relied upon as presence indicators for many years (Strachan, Jefferies $\&$ Chanin, 1996). Following a series of conflicting scat surveys, it has been argued that pine martens are now effectively extinct in England and Wales (Bright, Halliwell \& Mitchell-Jones, 2000), and a national reintroduction programme is at the public consultation

*All correspondence to: A. Davison, Department of Ecology and Evolutionary Biology, Biological Institute, Tohoku University, Aramaki-Aza-Aoba, Aoba-ku, Sendai 980-8578, Japan.

E-mail: a.davison@hgmp.mrc.ac.uk stage, partly funded by English Nature and the People's Trust for Endangered Species (Bright et al., 2000). As IUCN guidelines are against re-introductions while remnant populations exist (Anon, 1995), it is imperative that such crucial (and expensive) decisions are informed by entirely reliable field data.

An earlier study has already shown that otter, mink and polecat Mustela putorius scats may be confused when using morphology alone (Hansen \& Jacobsen, 1999), and accurate identification is also essential when carrying out dietary surveys (Hansen \& Jacobsen, 1999). DNA methods on scats, or 'molecular scatology' are a relatively new means of gleaning information from animals that may be otherwise difficult to survey. These methods were therefore used to test the ability of experienced marten naturalists to identify marten scats from foxes in the field, using samples from a well-established population of martens and foxes in Galloway, Scotland, as well as from England and Wales.

\section{MATERIALS AND METHODS}

\section{Sample collection}

During 1999-2000, 3 experienced marten field workers were employed to anonymously collect fresh marten 
scats using standard techniques (Lawrence \& Brown, 1967; Strachan et al., 1996), at different times across the same transects. Diagnostic characters (Strachan et al., 1996) such as the size, shape and odour were noted, so each sample could be given a confidence score of 'possible', 'probable', and 'certain' marten. One surveyor undertook further scat collections more widely in south-west Scotland, and in a sample of $10 \times 10 \mathrm{~km}$ squares in England and Wales, in regions where martens were probably present at low density (Messenger \& Birks, 2000). In addition, several other naturalists submitted scats, in the belief that they might be from martens. After field collection, scats were air-dried and stored deep frozen at $-20^{\circ} \mathrm{C}$ in individual plastic bags.

A trial exposure series was also undertaken to rule out the possibility that foxes counter-mark marten scats, potentially confusing their identification. This was achieved by placing outside 30 fresh scats from captive martens in an area where foxes are common, 10 at a time, and re-collecting them at 2-day intervals.

\section{DNA extraction}

DNA was then extracted from the scats using Nucleon ${ }^{(i x}$ phytopure kits. These kits were used because one of the main problems with faecal material is that contaminating mucopolysaccharides may inhibit downstream reactions. In brief, a small amount of material $(<0.1 \mathrm{~g})$ was scraped from the outer parts to enrich for mucosal cells. The protocol was then followed according to the manufacturer's instructions for plant DNA extraction, except for the addition of an extra chloroform step to remove excess insoluble residues.

\section{PCR reaction conditions}

The extractions and setting up of PCRs were carried out in a laboratory that had not been used previously for mammal work. For every scat extraction, another 'extraction blank' was used, to check for crossover contamination that could occur during DNA purification. Finally, PCR blanks were also used, without a PCR positive control.

Attempts were made to amplify and sequence an $\sim 200 \mathrm{bp}$ mitochondrial DNA control region fragment from all the samples, using specially designed carnivore-specific primers, either LRCB1 (5'TGGTCTTGTAAACCAAAAATGG-3') or LRBC3 (5'-AGACTCAAGGAAGAAGCAAC- $3^{\prime}$ ) and MARDH (5'-CATGCTTATATGCATGGGGC-3').

Nucleotide sequences were determined using either the dRhodamine or Big Dye ABI sequencing kit (Applied Biosystems), and easily aligned by eye. Species was identified by comparison with Martes, Vulpes, and Mustela sequences on the Genbank database. Most positive marten samples were confirmed by independent re-extraction, and a further round of PCR.

\section{RESULTS}

DNA was successfully extracted and amplified from $53 \%$ of scats (total extracted $=163$ ). Surprisingly, in Scotland $18 \%$ of identified 'marten' scats were from foxes (total identified $=56$; individual surveyor records were $9 \%, 29 \%$ and 19\% foxes, by DNA). In England and Wales, only one marten scat was found by DNA methods (from Caernarfonshire, Wales); all of the other 'marten' scats $(97 \%)$ were mistakenly collected from foxes $(n=28)$ or a polecat $(n=1)$.

As in previous surveys (Strachan et al., 1996; Bright et al., 2000), collectors were confident that they could identify marten scats, but this was not borne out by the DNA evidence: in eight fox scats from Galloway, three had been classed as 'certain' marten and two as 'probable'. There was also variation between regions: one person correctly identified all marten scats from Galloway, yet was always mistaken $(n=12)$ in the low density populations in England and Wales. The mistake may be general because all but one of the possible marten scats collected by the other naturalists in England and Wales were also from a fox $(n=18)$.

We extracted DNA and sequenced the PCR products from the captive marten scats that were used in the three trial exposures. Scats were identified by DNA methods in $70 \%, 100 \%$, and $100 \%$ of cases, following up to 20 days in the field (mean rainfall $=40 \mathrm{~mm}$ ). All amplified mitochondrial control region DNA of martens may rule out the possibility that fox countermarking confuses identification.

\section{DISCUSSION}

Surveys on pine martens scats, based on morphology, are unreliable because surveyors were mistaken in their belief that they could identify the scats. The surveys failed completely for endangered populations, partly because it is more difficult to find scats when an animal is at low density and territory marking ceases, but also because the surveyor's judgement was much worse.

As many studies of rare mammals rely on accurate identification from faeces, the methods for scat identification must be made more stringent, especially where it is known that an animal is endangered. Surveying from scats by morphological criteria is especially common in Britain, but the method may increase in use elsewhere; as a carnivore becomes rarer the animal is often protected by law, so it becomes difficult to survey by other means.

In the future, a multi-evidence approach should be adopted to monitor elusive mammals, involving DNA methods on scats, identification of species from cast hairs (Teerinck, 1991), camera traps, and non-leading 'sighting' questionaires (Messenger \& Birks, 2000; RuizOlmo, Saavendra \& Jiménez, 2001). Hairs collected from barbed wires at bait stations or tape outside dens can also been used for genetic studies (Woods et al., 1999; Sloane et al., 2000), although the problem remains 
in locating the animal in the first place. For large surveying efforts, such as national surveys, it may be cost effective to load large numbers of samples on to a microarray, subsequently screening them with species specific primers (J. Wetton, pers. comm.).

Unfortunately, routine DNA typing from faeces is costly and technically difficult, particularly using microsatellites (Gerloff et al., 1999; Kohn et al., 1999) because the DNA degrades rapidly. Therefore, studies are often restricted to using fresh samples, obtained after the animal is observed defaecating, i.e. the advantage of using faeces in these circumstances is their nonintrusiveness (Gerloff et al., 1999). Other recent studies have begun to use data from microsatellites to count and track individuals (Kohn et al., 1999; Ernest et al., 2000; Mowat \& Strobeck, 2000). However, high copy number means that mitochondrial DNA may be most useful for surveying species, as this study shows that it may be used in relatively old and rain-washed samples. In South America, where scat identification from morphology is complicated by a greater diversity of species, a recent molecular study was able to identify the species from which the scat originated (Farrell, Roman \& Sunquist, 2000). As in this study, criteria for identification based on scat morphology were shown to be incorrect.

A significant problem with all molecular work on scats is that only a proportion of samples ever yields DNA that is of sufficient quality to be amplifiable by the PCR (Murphy, Waits \& Kendall, 2000). For our study, the DNA may have degraded because the samples were not fresh, some being more than a month old when collected. There are also many other factors involved, such as the degree of rainfall. Slugs have even been observed to consume nearly a whole scat within 24 h (J. D. S. Birks, pers. obs.). This study raises the possibility that field workers or better, dogs, could be trained to identify scats. It may be necessary to use scats from wild animals for the training, following identification by molecular means, as the diet of captive animals might yield scats with different morphologies and odours.

\section{Acknowledgements}

We are especially grateful to The Vincent Wildlife Trust for funding this project, and to the three anonymous marten surveyors. Thanks also to the staff at Nottingham for hosting $\mathrm{AD}$ and $\mathrm{RCB}$, especially Bryan Clarke, David Parkin and Linda Parkin. Comments from Jon Bridle, Huw Griffiths and two reviewers greatly improved the manuscript.

\section{REFERENCES}

Anon (1995). IUCNISSC guidelines for re-introductions. Gland, Switzerland: Species Survival Commission.

Bright, P., Halliwell, E. \& Mitchell-Jones, T. (2000). Public consultation document on the return of the pine marten to England. London: People's Trust for Endangered Species.

Farrell, L. E., Roman, J. \& Sunquist, M. E. (2000). Dietary separation of sympatric carnivores identified by molecular analysis of scats. Mol. Ecol. 9: 1583-1590.

Gerloff, U., Hartung, B., Fruth, B., Hohmann, G. \& Tautz, D. (1999). Intracommunity relationships, dispersal pattern and paternity success in a wild living community of bonobos (Pan paniscus) determined from DNA analysis of faecal samples. Proc. R. Soc. London B Biol. Sci. 266: 1189-1195.

Hansen, M. M. \& Jacobsen, L. (1999). Identification of mustelid species: otter (Lutra lutra), American mink (Mustela vison) and polecat (Mustela putorius), by analysis of DNA from faecal samples. J. Zool. (Lond.) 247: 177-181.

Kohn, M. H., York, E. C., Kamradt, D. A., Haugt, G., Sauvajot, R. M. \& Wayne, R. K. (1999). Estimating population size by genotyping faeces. Proc. R. Soc. London B Biol. Sci. 266: $657-663$

Lawrence, M. J. \& Brown, R. W. (1967). Mammals of Britain, their tracks, trails and signs. London: Blandford.

Messenger, J. E. \& Birks, J. D. S. (2000). Monitoring the very rare: pine marten populations in England and Wales. In Mustelids in a modern world. Management and conservation aspects of small carnivore: human interactions: 217-230. Griffiths, H. I. (Ed.). Leiden: Backhuys.

Mowat \& Strobeck, C. (2000). Estimating population size of grizzly bears using hair capture, DNA profiling, and markrecapture analysis. J. Wildl. Manage. 64: 184-193.

Murphy, M. A., Waits, L. P. \& Kendall, C. (2000). Quantitative evaluation of fecal drying methods for brown bear DNA analysis. Wildl. Soc. Bull. 28: 951-957.

Ruiz-Olmo, J., Saavedra, D. \& Jiménez, J. (2001). Testing the surveys and visual and track censuses of Eurasian otters (Lutra lutra). J. Zool. (Lond.) 253: 359-369.

Sloane, M. A., Sunnucks, P., Alpers, D., Beheregaray, L. B. \& Taylor, A. C. (2000). Highly reliable genetic identification of individual northern hairy-nosed wombats from single remotely collected hairs: a feasible censusing method. Mol. Ecol. 9: $1233-1240$.

Strachan, R., Jefferies, D. J. \& Chanin, P. R. F. (1996). Pine marten survey of England and Wales 1987-1988. Peterborough: Joint Nature Conservation Committee.

Teerinck, B. J. (1991). Hair of west European mammals: atlas and identification key. Cambridge: Cambridge University Press.

Woods, J. G., Paetkau, D., Lewis D., McLellan, B. N., Proctor, M. \& Strobeck, C. (1999). Genetic tagging of free-ranging black and brown bears. Wildl. Soc. Bull. 27: 616-627. 